Jose M. Fedriani - Francisco Palomares · Miguel Delibes

\title{
Niche relations among three sympatric Mediterranean carnivores
}

Received: 17 November 1998 / Accepted: 1 May 1999

\begin{abstract}
Previous studies carried out in the Doñana National Park reported that red foxes (Vulpes vulpes) were killed by Iberian lynxes (Lynx pardinus), whereas similar-sized Eurasian badgers (Meles meles) were not. Therefore, we predicted that fox would avoid lynx predation risk by niche segregation whereas we did not expect such a segregation between badger and lynx. As an approach for evaluating our predictions, we compared their diet, activity patterns, and habitat use in an area of Doñana where the three carnivores are sympatric. Lynxes preyed almost uniquely on European rabbits (Oryctolagus cuniculus), and though badgers and foxes were omnivorous, rabbits also were a major prey, resulting in high overlaps throughout the year. However, badgers preyed largely on small rabbits, whereas lynxes and foxes preyed mainly on medium-sized rabbits. There were also interspecific differences in activity patterns. Maximum levels of activity among lynxes were during sunrise and dusk (49-67\%). Foxes were most active during dusk and night (34-67\%), and badgers were mainly nocturnal $(53-87 \%)$. Though there were seasonal differences in the amount of activity of each species, specific activity patterns changed little throughout the year. There was a strong difference in annual habitat use by the three species $(P<0.0001)$. Lynxes used mainly the Mediterranean scrubland during both the active $\left(\mathrm{P}_{\mathrm{MAX}}\right)$ and the resting $\left(\mathrm{P}_{\mathrm{MIN}}\right)$ periods. During $\mathrm{P}_{\mathrm{MIN}}$, foxes used the Mediterranean scrubland intensively (40\% of locations on average), but during $\mathrm{P}_{\mathrm{MAX}}$, they used the pastureland much more intensively despite this habitat being poorer in their main prey (rabbits). As a consequence, foxes and lynxes exhibited segregation in their habitat use during the active period. Badgers also
\end{abstract}

J.M. Fedriani $(\bowtie) \cdot$ F. Palomares $\cdot$ M. Delibes Department of Applied Biology,

Estacion Biologica de Doñana,

CSIC, Avda. Maria Luisa s/n,

E-41013 Sevilla, Spain

e-mail: fedriani@ebd03.csic.es, Fax: +34-95-4621125 used the Mediterranean scrubland intensively, especially during $\mathrm{P}_{\mathrm{MIN}}$. There were no seasonal differences in habitat use for lynx and fox, but there was for badgers $(P<0.015)$. Within the study area, the three species selected habitat suggesting they were sensitive to factors such as vegetation and prey abundance. However, in general, carnivore habitat use did not correlate with rabbit abundance. We propose that foxes avoided lynxes by using, during activity, habitats not frequented by lynxes, and that a low predation risk associated with the distinctive foraging mode of badgers may facilitate its coexistence with other carnivores.

Key words Mediterranean ecosystem - Lynx pardinus . Meles meles $\cdot$ Niche relations $\cdot$ Vulpes vulpes

\section{Introduction}

Ecologists have long considered that niche segregation serves to reduce exploitative competition and thus facilitates coexistence of similar species (Pianka 1978). Increasingly, however, emphasis is placed on the role of intraguild predation (sensu Polis et al. 1989) on niche segregation as a consequence of the antipredator behavior of species under predation risk (Sih et al. 1985). We chose one top and two intermediate sympatric predators (one of them frequently killed by the top predator) to test the hypothesis of greater segregation among the two interfering species in some of the most important dimensions of the ecological niche (habitat, food, and time; Schoener 1974).

In Mediterranean ecosystems, trophic relations among sympatric carnivores have been studied (e.g., Jaksic and Delibes 1987) but multidimensional niche approaches are scare (Palomares and Delibes 1991), although they are essential for a comprehensive understanding of the niche relation among predators (Wiens 1993). In the Mediterranean Doñana National Park (southwest Spain), the Iberian lynx (Lynx pardinus, 9$12 \mathrm{~kg}$ ), Eurasian badger (Meles meles, 7-8 kg), and the 
red fox (Vulpes vulpes, 5-7 kg) occur in sympatry. Previous studies identified the importance of the European rabbit (Oryctolagus cuniculus) in the diet of these three carnivores (Delibes 1980; Rau et al. 1985; Martin et al. 1995). However, little is known about either activity patterns or habitat use by both foxes and badgers in Doñana, although elsewhere they have been reported as mainly nocturnal and crepuscular (Macdonald 1984) and as habitat generalist species (Ginsberg and Macdonald 1991; Neal and Chesseman 1996). Lynxes in Doñana are crepuscular (Beltran and Delibes 1994) and habitat specialists (e.g., Palomares et al. 1991). Because carnivore habitat use often correlates with prey abundance (e.g., Murray et al. 1994) and habitat-related variations in rabbit abundance occur in Doñana (Beltran 1991; Palomares and Delibes 1997), we expected lynx, fox, and badger habitat use to correlate with rabbit abundance in relation to the importance of rabbits in their diet. However, recent studies on carnivores emphasize the role of interference competition in shaping their niches (Iriarte et al. 1990; Hersteinsson and Macdonald 1992; Mills and Biggs 1993). In Doñana, lynxes kill foxes (Palomares et al. 1996; Fedriani 1997); thus, we expected some temporal and/or spatial segregation between those sympatric species (Schoener 1974). No aggressive interactions between lynxes and badgers are known; therefore, we did not expect such a segregation. Little is known about fox-badger relationships in Doñana, but in other areas, cases of both aggressive and peaceful encounters have been reported (Neal and Chesseman 1996). Thus, we had no clear expectations about their potential segregation of resource use in Doñana.

Our specific goals were: (1) to estimate the relative importance of different prey in carnivore diets, their seasonal variations in prey use and the degree of interspecific food overlap, (2) to describe the activity patterns of the three carnivores, to estimate seasonal and interspecific differences, and to assess the degree of interspecific overlap in activity patterns, (3) to assess their habitat use and preference during their resting and active periods, to evaluate their seasonal and interspecific variations, and to estimate the interspecific overlap in habitat use, and (4) to explore whether carnivore habitat use correlated with rabbit abundance. Annual diets of both foxes and badgers have been published (Fedriani 1996; Fedriani et al. 1998), and data on lynx habitat use is currently being reviewed (F. Palomares, M. Delibes, P. Ferreras, J.M. Fedriani, J. Calzada, E. Revilla, unpublished data).

\section{Materials and methods}

Study area

Our field work was conducted from November 1992 through May 1995 in the northern portion of the Doñana National Park $\left(37^{\circ} 9^{\prime} \mathrm{N}\right.$, $6^{\circ} 26^{\prime} \mathrm{W}$ ), located on the west bank of the Guadalquivir River mouth in southwestern Spain. The climate is Mediterranean sub- humid, characterized by dry, hot summers and mild, wet winters Average annual rainfall is $500-600 \mathrm{~mm}$.

Marshes, scrubland and dunes are the three main habitats of Doñana (Valverde 1958), though a finer classification revealing six habitat types is possible within our specific study area. (1) The Mediterranean scrubland is mainly formed by Pistacea lenticus shrubs with variable brush of Halimium halimifolium and scattered Quercus suber and Pirus bourgaena trees. (2) Pastureland is an open area of Juncus spp., Silene laeta and Gaudinia fragilis but with some $H$. halimifolium brushes and scattered $O$. suber and Olea europaea. (3) Grassland mainly surrounds the Mediterranean scrubland and the pastureland, and includes some patches of variable size dominated by Asphodelus ramosus and Armeria gaditana. (4) Tree plantations are comprised of Pinus pinea and Eucalyptus spp. with shrubs of $P$. lenticus common. (5) Marshes are open areas where trees and scrubs are practically absent. (6) Ash forest (Fraxinus sp.) occurs in several patches, the two largest associated with natural streams, and has shrubs of $P$. lenticus (Fig. 1).

Numbers of individuals of the target carnivore species within the study area were estimated by Fedriani (1997), and ranged from 9 to 12 lynxes, from 9 to 16 badgers, and from 26 to 42 foxes. Other mammalian carnivore species also abundant in our study area were the Egyptian mongoose (Herpestes ichneumon) and the common genet (Genetta genetta).

Food habits

Carnivore diets were assessed through feces analyses. Feces were collected weekly from November 1992 to December 1994, and all samples were well distributed over the year. Total sample sizes were 320 for fox, 279 for badger, and 240 for lynx. The analysis of feces was made by standard methods (Reynolds and Aesbischer 1991), and prey items identified were categorized into six types: lagomorphs, other vertebrates, carrion, invertebrates, fruit, and miscellaneous. The importance in the diet of each prey type was quantified by two methods: (1) frequency of occurrence = number of feces containing each prey type $\times 100 /$ total number of feces; $(2)$ fresh biomass ingested $=$ dry weight of remains of a particular prey type $\times$ its correction factors $(C F) \times 100 / \Sigma$ (dry weight of remains of each prey type $\times \mathrm{CF}$ of each prey type). Correction factors were obtained from the literature (Lockie 1959; Aldama 1993; Martín et al. 1995). Rabbits found in feces were classed into three size categories (small, $\leq 200 \mathrm{~g}$; medium, $>200$ but $\leq 800 \mathrm{~g}$; large, $>800 \mathrm{~g}$ ) by comparing their remains (mainly bones and nails) with those from reference specimens of known weight. Because the availability of rabbits varies seasonally in Doñana (Delibes and Calderón 1979; Rogers et al. 1994), we considered the diets of the autumn/winter (November-February), spring (March-June), and summer (July-October) periods separately.

Differences in the occurrence of particular prey categories among compared diets were detected by $\chi^{2}$ analysis of contingency tables, or by Fisher exact test when the percentage of expected values lower than five in the contingency tables was higher than $20 \%$ (Wells and King 1980). The sequential Bonferroni confidence intervals (Rice 1989) were used in multiple comparisons to control the experimentwise error. Seasonal food overlap was estimated for each pair of species with Pianka's (1973) index, using percentages of fresh biomass ingested by carnivores. For food overlap calculations, vertebrates and fruit were classed to species or genus and invertebrates to order (Greene and Jaksic 1983).

Animal capture, immobilization, and radio-tagging

Because activity patterns and habitat use of carnivores were studied by radio-tracking, the three species of carnivores were captured using coil-spring traps (Victor no. 2, Woodstream, Pennsilvania) and baited box-traps. Once captured, the animals were immobilized with an intramuscular injection of ketamine hydrochloride $(50 \mathrm{mg}$ $\mathrm{ml}$, Ketolar, Parke-Davis) and xylazine hydrochloride $(23.3 \mathrm{mg} / \mathrm{ml}$, Rompun, Bayer). Drug doses, induction, and recovery times are 
Fig. 1 Sketch map of the study area with the main habitat types. Broken line represents the Doñana National Park boundaries. Frame tick marks represent $500 \mathrm{~m}$ spacing

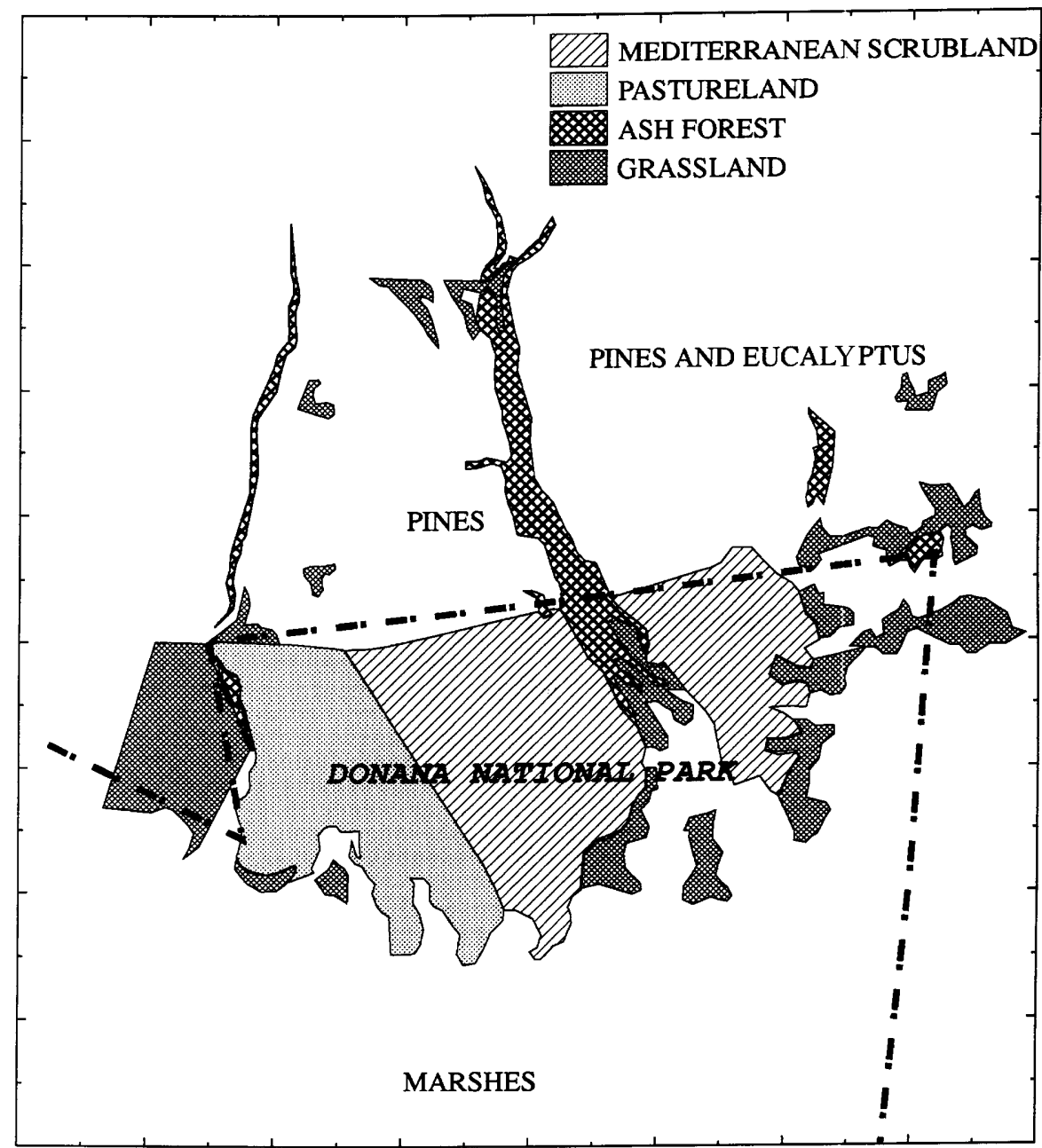

described in Ferreras et al. (1994) for lynxes, in Travaini et al. (1992) for foxes, and in Travaini et al. (1994) for badgers. Captured animals were fitted with radio-collars, and animal location was estimated through triangulation. Our tracking system and procedures were similar to those described by Ferreras et al. (1997); thus, we assumed our location error was similar (usually less than $100 \mathrm{~m})$.

\section{Activity patterns}

Carnivore activity was treated as a dichotomous variable: active or not active. Activity was determined by specific sensors incorporated in radio-collars. Intensive $24-\mathrm{h}$ radio-tracking periods were conducted during which activity was determined at $1-\mathrm{h}$ intervals. The total number of intensive $24-\mathrm{h}$ radio-tracking periods conducted were 58 for lynx (ten individuals), 37 for fox (eleven individuals) and 43 for badger (eight individuals). For analyses, the 24-h cycle was divided into four periods (day, night, dusk, and sunrise). Duration of day and night varied through the year, but dusk and sunrise were assumed to be of constant duration $(2 \mathrm{~h})$ (details in Fedriani 1997). We used generalized linear models (GLM) fitted with the program GLIM (Baker 1987) to analyze the results. Because of the dichotomous nature of the response variable (percent of activity), we assumed that errors followed a binomial distribution (Crawley 1993). The model was fitted considering three factors: species, season, and period. The significance of each factor and their interactions was assessed by stepwise backwards elimination from the full model. The increase in deviance of the model when a factor was removed was checked against the distribution chi-square with the same degrees of freedom $(d f)$ as the increase in $d f$ of the model. When the ratio deviance/df of the initial minimum model suggested overdispersion in the data (Crawley 1993), the deviance of the model was scaled and the significance of the final model rechecked. As a measurement of the seasonal interspecific overlap in activity, we calculated Pianka's index using percentages of activity in the four defined periods.

\section{Habitat use}

We used the six habitats detailed above for habitat use analyses. The habitat composition of the total study area [defined as minimum convex polygon encompassing all radio-locations of all the individuals of the three species; hereafter total minimum polygon (TMP)] and of each individual's home range, and the proportion of radio-locations from each animal within each habitat type, were calculated using RANGES V (Kenward and Hodder 1996). Home ranges were estimated from the minimum convex polygons including the $95 \%$ of locations. To exclude the outer locations $(5 \%)$, we used the harmonic-mean method (Dixon and Chapman 1980). For each individual, radio-locations were separated by at least $12 \mathrm{~h}$ to avoid the issue of pseudoreplication. Individuals that were located less than ten times were not used in analyses. After this selection, lynxes were located on average 111 times $(1 \mathrm{SD}= \pm 122$, $n=11$ ), foxes 78 times (1SD $= \pm 74, n=18)$, and badgers 62 times $(1 \mathrm{SD}= \pm 39, n=10)$. 
Because habitat use by carnivores may differ between resting and active periods (Palomares and Delibes 1992), we defined both periods of relative minimum $\left(\mathrm{P}_{\mathrm{MIN}}\right)$ and relative maximum $\left(\mathrm{P}_{\mathrm{MAX}}\right)$ activity, using the mean percentage of activity of their total 24-h tracking periods as a threshold value. $\mathrm{P}_{\text {MIN }}$ was defined as the interval during which a specific carnivore species showed consistently a percent of activity lower than its mean percentage of activity. This period was $0900-1600$ for lynx, 0300-1800 for fox, 0500-1900 hours for badger. $\mathrm{P}_{\text {MAX }}$ was defined as the rest of the circadian cycle. MANOVA tests (SAS 1990) were used to test intraspecific differences between seasons (as defined above) and active-resting periods, and annual interspecific differences in habitat use, always using percentages of radio-locations as the habitat use estimate. Once overall significant differences were detected, we applied univariate analyses (ANOVA) for each habitat type using the Bonferroni method. For these analyses, we used the arcsine transformation of percentages of radio-locations (Zar 1984). Pianka's index was calculated using percentages of radio-locations to assess the degree of interspecific seasonal habitat use overlap.

We determined if there was annual habitat selection through the use of compositional analysis (Aebischer et al. 1993). Overall deviation from random utilization was tested with $\chi^{2}$ as the test statistic with $H-1$ degrees of freedom $(H=$ number of habitat types available). If habitat utilization was significantly non-random $(P<0.05)$, then the habitat types can be placed into a rank order of preference by constructing a ranking matrix. Departures from random preference for specific habitat types were then tested by Student's $t$-test. Because carnivores may respond to both landscape and local attributes (e.g., Pedlar et al. 1997), we first considered habitat available within the TMP and compared this with individual home range habitat composition, and then we considered habitat available within individual home ranges and compared this with the percentage of locations of the individuals (Aebischer et al. 1993).

\section{Rabbit abundance and relationship with carnivore habitat use}

Rabbit abundance was estimated in Mediterranean scrubland, ash forest, pastureland, tree plantations and marshes through visual censuses from a vehicle which travelled at $20 \mathrm{~km} / \mathrm{h}$ along fixed transects. The observer counted rabbits seen within $10 \mathrm{~m}$ of the line transect. The surveys started $1 \mathrm{~h}$ before dusk (coinciding with a peak in rabbit activity) and lasted approximately $1.5 \mathrm{~h}$. Each survey was repeated on 3 consecutive days, but we only considered the replicate in which we observed the highest number of rabbits. The surveys were carried out every $2-3$ months during a 12-month period. A rabbit abundance index for each census and habitat was calculated dividing the number of rabbits counted by the distance covered $(\mathrm{km})$. Then we averaged the indexes of different surveys yielding an annual rabbit abundance index for each habitat. A mean rabbit abundance index was also estimated for each season by averaging indexes of different habitats. Differences in rabbit abundances among habitat types and seasons were tested by GLM (SAS 1990). To assess whether carnivore habitat use correlated with rabbit abundance, we quantified habitat use for each carnivore species as the mean percentage of area covered by each habitat type within individual home range and as the mean number of radiolocations during the active period in each habitat type divided by square kilometers of available habitat within the TMP. For each species, Spearman rank correlation coefficients were calculated between carnivore habitat use and rabbit abundance.

\section{Results}

\section{Diets}

Lynx diet was almost uniquely based on rabbits, comprising seasonally $97-99 \%$ of the biomass ingested (Table 1). Rabbits eaten by lynx were mainly of the

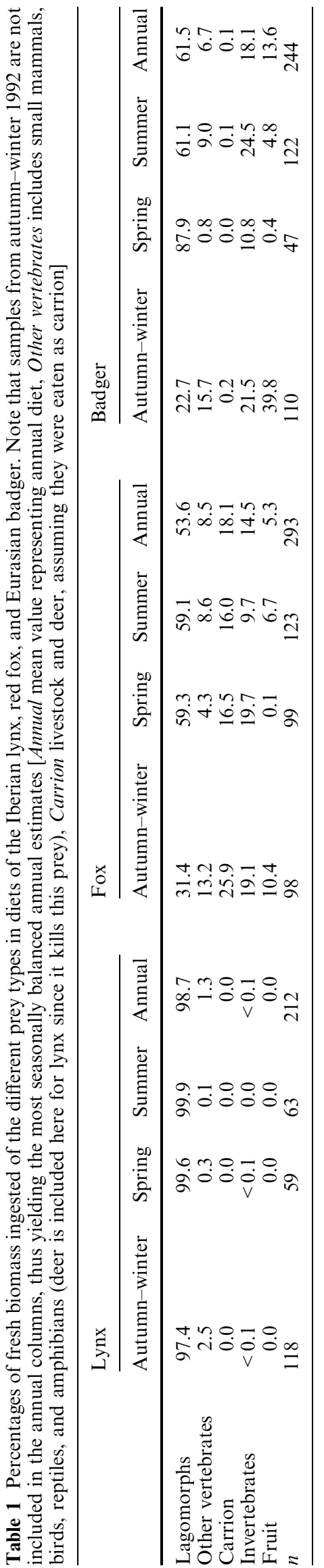


medium-size category $(89 \%, n=209$, Fig. 2). Other prey types were of very little importance, and thus we did not detect seasonal differences in lynx food habits (Fisher exact test, $P=0.186$ ).

Fox diet was primarily based on rabbits, which annually comprised $54 \%$ of the biomass ingested and occurred in $54 \%$ of scats analyzed. Rabbits eaten by foxes were mainly of the medium-size category $(82 \%$, $n=100$, Fig. 2). Carrion and invertebrates were also of relatively important (Tables 1,2), but other food types were annually of little importance. Seasonal fox diets differed significantly $\left(\chi^{2}=48.2, d f=10, P<0.001\right)$. During autumn/winter, foxes consumed less rabbits than they did in spring $\left(\chi^{2}=13.57, d f=1, P<0.01\right)$ and summer $\left(\chi^{2}=27.4, \quad d f=1, \quad P<0.001 ;\right.$ Table 2$)$. During autumn/winter, foxes consumed more fruit than they did in spring $\left(\chi^{2}=33.8, d f=1, P<0.001\right.$; Table 2). We did not detect differences between spring and summer fox diets $(P=0.129)$.

The annual badger diet was also based on rabbits, which comprised $61 \%$ of the biomass ingested and occurred in $37 \%$ of the scats analyzed. Rabbits eaten by badgers were mainly of the small $(48 \%)$ or medium $(47 \%)$ size categories ( $n=60$; Fig. 2). Invertebrates and fruit were also relatively important (Table 1$)$. Seasonal badger diets differed significantly $\left(\chi^{2}=115.9, d f=10\right.$, $P<0.001)$. Differences were significant for all pairs of seasonal diet comparisons (all $P<0.001$ ). During autumn/winter, badgers consumed less rabbits than they did in spring $\left(\chi^{2}=48.9, d f=1, P<0.001\right.$; Table 2$)$ and summer $\left(\chi^{2}=18.3, d f=1, P<0.001\right)$, but consumed more fruit than they did during those seasons (all $\chi^{2}>61.9, d f=1$, all $\left.P<0.001\right)$. Badgers consumed

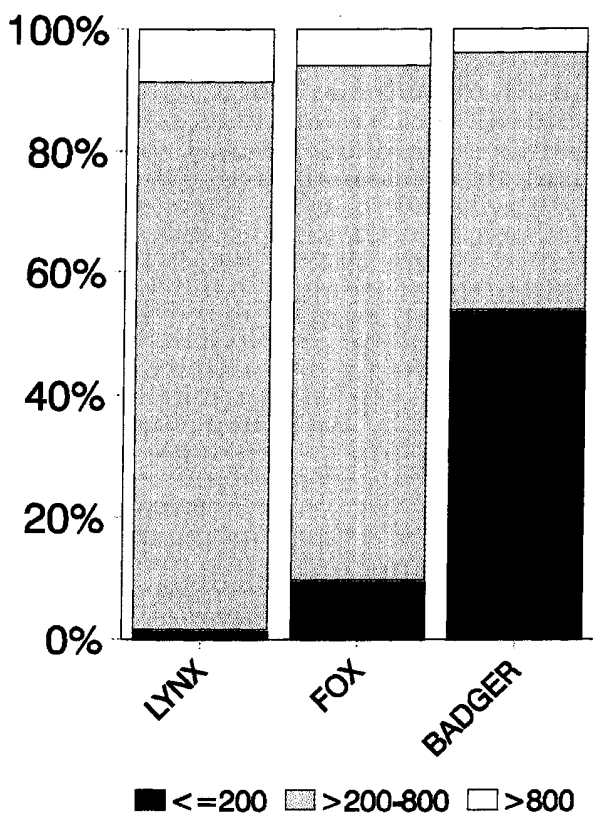

Fig. 2 Percent by numbers of different rabbit size types preyed on by the three carnivores studied. Sample sizes were 209, 100, and 60 for lynx, fox, and badger, respectively

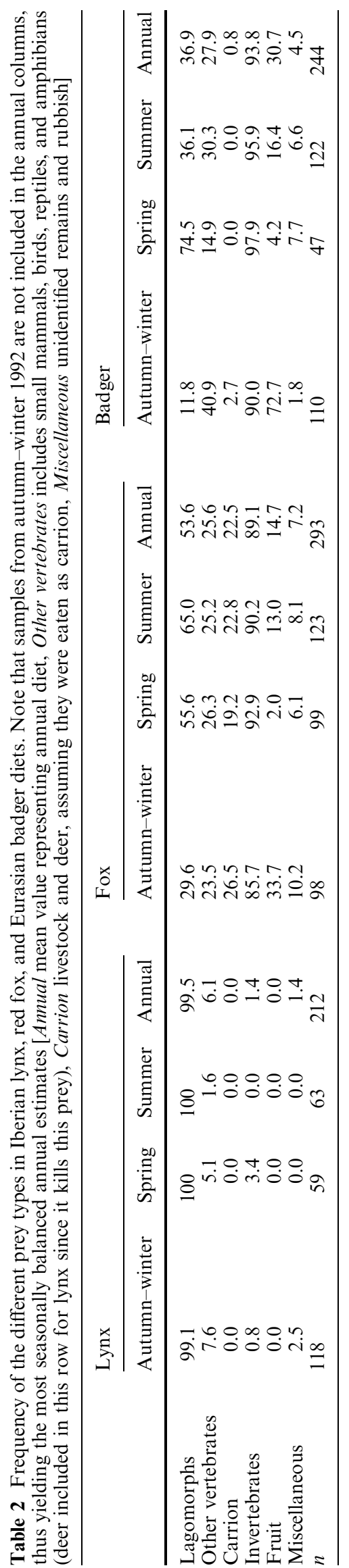


more rabbits in spring than they did in summer $\left(\chi^{2}=\right.$ 20.1, $d f=1, P<0.001$; Table 2).

Differences in annual and seasonal diets of the three species were significant for all pairs of comparisons $(P<0.001)$. Annually and seasonally, lynxes consumed more rabbits than did foxes and badgers $(P<0.001)$, and badgers were more frugivorous than foxes $(P<0.001)$, but consumed less carrion than did foxes $(P<0.001$; Table 2). Despite these strong interspecific differences in the occurrence of the prey types, the seasonal food overlap indices based on biomass ingested were always high (Fig. 3) due to the high rabbit biomass in all carnivore diets. The minimum trophic overlap values were always during autumn/winter, coinciding with the minimum rabbit consumption by foxes and badgers (Tables 1,2). Because of the high importance of rabbits in all carnivore diets, we also tested whether carnivores preyed annually on different sizes of rabbits. Carnivores differed in the size class of rabbits preyed $\left(\chi^{2}=101.9, d f=4, P<0.0001\right.$; Fig. 2). These differences were significant for all pairs of species comparisons (all $P<0.002$ ). Badgers consumed more small and less medium-sized rabbits than did foxes and lynxes (all $P<0.001)$. Foxes consumed more small rabbits than did lynxes $(P<0.001$; Fig. 2$)$.

\section{Activity patterns}

Lynx showed high seasonal percentages of activity at all periods of the circadian cycle defined and the minimum values always occurred during daytime (Fig. 4). Highest seasonal lynx activity always occurred during dusk (Fig. 4), and ranged from 59 to $67 \%$. Seasonal lynx percentages of activity during sunrise $(49-57 \%)$ were similar to those during daytime (44-53\%). Seasonal differences in lynx percentage activity were low (Fig. 4).

Foxes were most active during dusk and night (seasonal percentages of activity ranged $42-67 \%$ and $34-47 \%$, respectively). During sunrise, percentages of activity were intermediate (27-35\%) and during the day, minimal (11-15\%; Fig. 4). The highest seasonal percentages of activity occurred during spring, whereas differences between autumn/winter and summer were of little importance (Fig. 4).

Badgers were mainly nocturnal. Night seasonal percentages of activity ranged from 53 to $87 \%$. During dusk they showed greater seasonal percentages of activity than during sunrise (30-65\% vs $10-31 \%$, respectively). During daytime, the seasonal percentage of activity estimated were very low (4-15\%). Seasonally, badgers showed highest percentages of activity during spring, whereas they showed similar percentages of activity in summer and autumn/winter (Fig. 4).

The GLM analysis indicated that all factors considered (species, season, and period) affected significantly the percentage of activity (all $P<0.001$; see Table 3 ). There were strong interspecific differences in the circadian patterns (interaction species $\times$ period, $P<0.0001$;
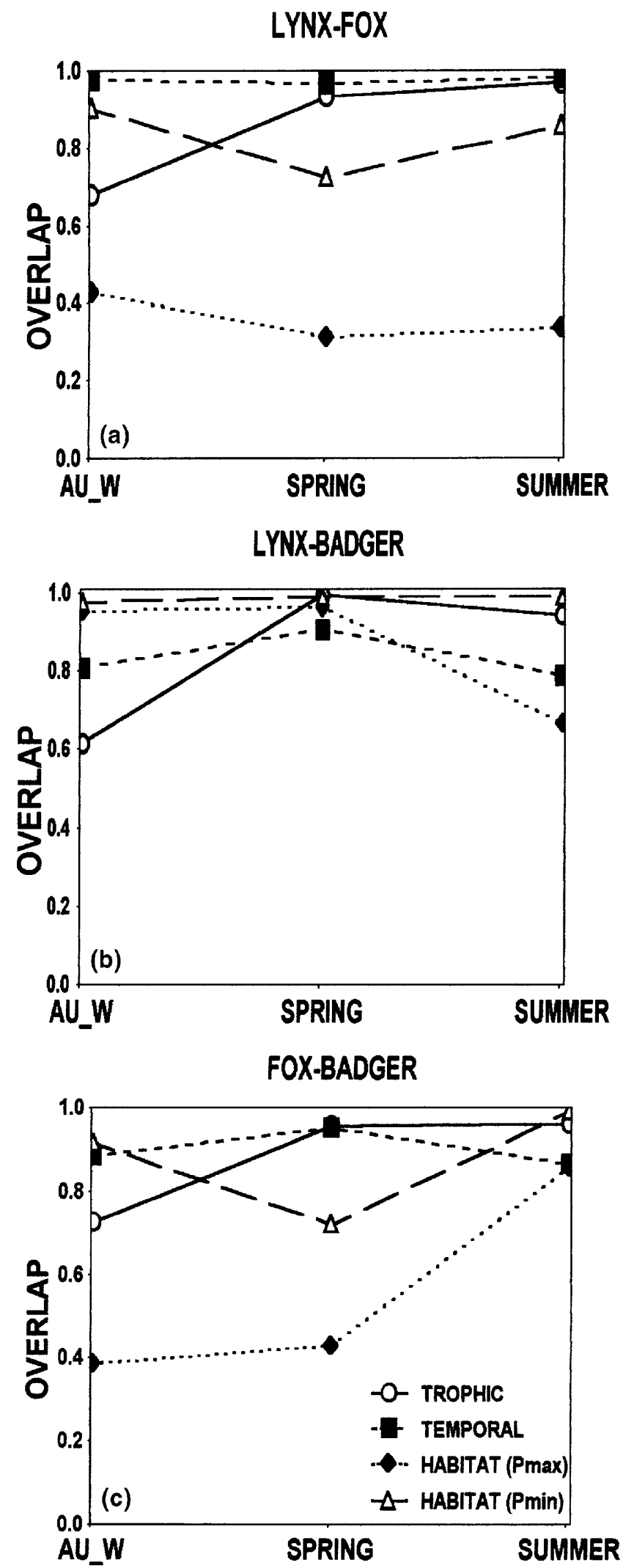

Fig. 3a-c Interspecific seasonal overlap values (measured as Pianka's indices) in diet, activity patterns, and habitat use during both periods of relative maximum $\left(\mathrm{P}_{\mathrm{MAX}}\right)$ and relative minimum $\left(\mathrm{P}_{\mathrm{MIN}}\right)$ activity ( $A U_{-} W$ autumn-winter) 
Fig. 4a-c Seasonal percentages of activity in each period shown by the three carnivore species studied ( $A U-W$ autumn-winter)
Lynx

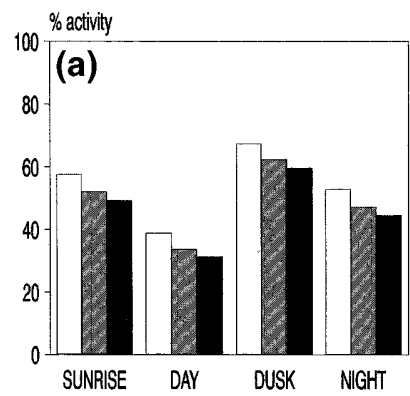

Table 3). This result indicates, for example, that whereas lynxes changed their activity little through the circadian cycle, badgers were mainly nocturnal and foxes were predominantly crepuscular (Fig. 4). We also detected interspecific differences in seasonal percentages of activity (interaction species $\times$ season, $P<0.001$ ). This result indicates, for example, that lynxes were more ac-

Table 3 Analysis of deviance for the variable percent of activity for the three carnivore species studied. Full model: deviance $=$ 217.2 $d f=196$. Significance of each factor and interaction was assessed by backwards elimination from the full model. Scale parameter $=2.21$

\begin{tabular}{lcccrl}
\hline Source & $\begin{array}{l}\text { Increment } \\
\text { in } \\
\text { deviance }\end{array}$ & $\begin{array}{l}\text { Reduction } \begin{array}{l}\text { in } \\
\text { d } f\end{array} \\
\text { increment } \\
\text { in deviance }\end{array}$ & & \\
\hline Season & 31.2 & 6 & 5.2 & 4.7 & $<0.001$ \\
Species & 105.2 & 12 & 8.8 & 7.9 & $<0.0001$ \\
Period & 233.4 & 9 & 14.8 & 13.4 & $<0.0001$ \\
Season $\times$ period & 210.6 & 6 & 1.1 & 0.9 & n.s. \\
Season $\times$ species & 23.5 & 4 & 5.9 & 5.3 & $<0.001$ \\
Species $\times$ period & 43.0 & 6 & 7.2 & 6.5 & $<0.0001$ \\
\hline
\end{tabular}

Table 4 Annual mean percentages of radio-locations ( $\%$ loc., $\pm 1 \mathrm{SD})$ during both periods of relative maximum $\left(\mathrm{P}_{\mathrm{MAX}}\right)$ and relative minimun activity $\left(\mathrm{P}_{\mathrm{MIN}}\right)$ and mean percentages of individual home range habitat composition $( \pm 1 \mathrm{SD})$ for the three carnivores
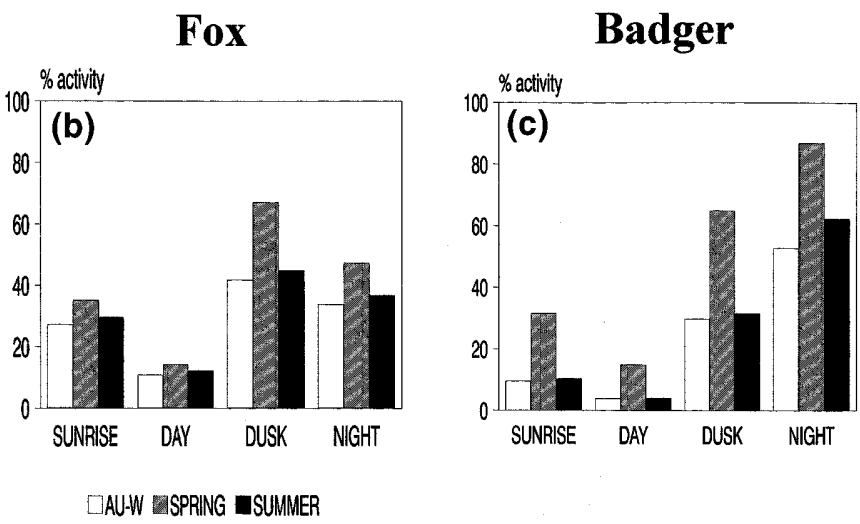

tive during autumn/winter, whereas foxes and badgers were more active during spring (Fig. 4). Overlap values in activity patterns were always high. Minimum values always occurred for lynx-badger (Fig. 3).

\section{Habitat use}

There were no differences in seasonal lynx habitat use $(F=0.903, d f=12, P=0.550)$ nor between periods of relative minimum $\left(\mathrm{P}_{\mathrm{MIN}}\right)$ and maximum $\left(\mathrm{P}_{\mathrm{MAX}}\right)$ activity $(F=0.865, d f=6, P=0.630)$. Mediterranean scrubland was the only habitat used by all individual lynxes, and clearly to a major extent (58-63\% of locations on average; Table 4); pastureland was the least used habitat ( $1-4 \%$ on average). The remaining habitat types were used to a similar extent (6-12\%; Table 4). The annual home range selection made by lynxes within the study area was not random (11 animals, $\chi^{2}=20.6, d f=5$, $P<0.001)$. They selected habitats in the following order: Mediterranean scrubland $>$ grassland $>$ ash forest $>$ marshes $>$ tree plantations $>$ pastureland. Mediterranean scrubland was selected significantly more than the

studied. Percentages of habitat types available within the minimum convex polygon encompassing all radio-locations (TMP) are also shown ( $n$ number of individuals considered)

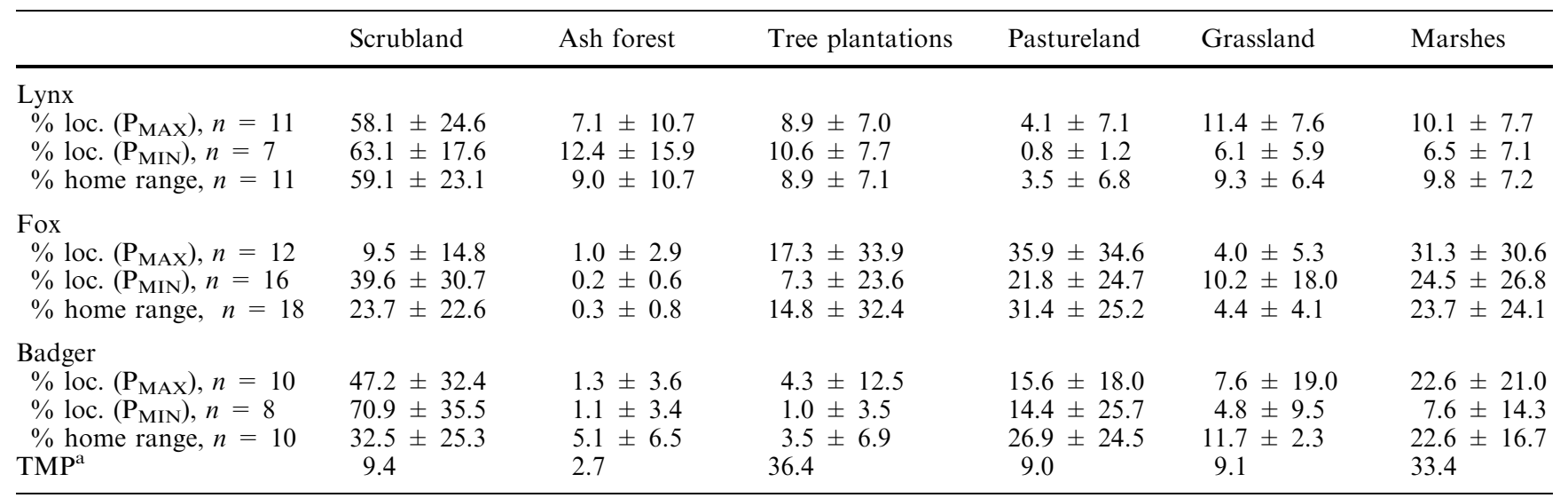

${ }^{\text {a }}$ Total area $=51.5 \mathrm{~km}^{2}$ 
other habitat types (all $t>2.9, d f=10$, all $P<0.05$ ). Grasslands were used significantly more than tree plantations and pastureland (all $t>2.5, d f=10$, all $P<0.05)$. Lynxes within their individual home ranges did not show evidence of any habitat preference $(P>0.10)$.

There were no seasonal differences in fox habitat use $(P=0.684)$, but their habitat use differed significantly between $\mathrm{P}_{\mathrm{MIN}}$ and $\mathrm{P}_{\mathrm{MAX}}(F=2.961, d f=6, P=$ $0.015)$. Differences were significant only for Mediterranean scrubland $(F=15.0, d f=1, P<0.01)$. During the $\mathrm{P}_{\text {MIN }}$ period, Mediterranean scrubland was clearly the most used habitat type $(40 \%$ of locations on average, Table 4), followed by marshes and pastureland used, on average, $25 \%$ and $22 \%$, respectively. The remaining habitat types were little used. However, during $\mathrm{P}_{\mathrm{MAX}}$, foxes were mainly located on pastureland and marshes (on average $36 \%$ and $31 \%$, respectively), while on average on only $9 \%$ of occasions were they located on the Mediterranean scrubland (Table 4). The annual home range selection made by foxes within the study area was not random (18 animals, $\chi^{2}=15.2$, $d f=5, \quad P<0.01)$. They selected habitats in the following order: pastureland $>$ Mediterranean scrubland $>$ grassland $>$ marshes $>$ ash forest $>$ tree plantations. There was no significant difference between the four top-ranking habitat types (all $P>0.05$ ), but there was a clear contrast between those and the two lowerranking ones (all $t>2.2, d f=17$, all $P<0.05$ ). Within individual home ranges, fox habitat use was not random during the $\mathrm{P}_{\mathrm{MIN}}$ (16 animals, $\chi^{2}=12.82$, $d f=5, P<0.05)$. They selected the habitats in the following order: Mediterranean scrubland $>$ grassland $>$ tree plantations $>$ ash forest $>$ marshes $>$ pastureland. Mediterranean scrubland was significantly preferred over all other habitat types except for grassland (all $t>2.3, d f=15$, all $P<0.05$ ) and there were no other significant habitat preferences. In contrast, during the $\mathrm{P}_{\mathrm{MAX}}$, there was no evidence of habitat selection within their home ranges $(P>0.1)$.

There were significant seasonal differences in badger habitat use $(F=2.432, d f=12, P<0.015)$. Seasonal differences were significant for Mediterranean scrubland and pastureland (all $F>8.4, d f=2$, all $P<0.01$ ). During autumn/winter and spring, badgers used mostly Mediterranean scrubland (67 and $95 \%$ of radio-locations on average during $\mathrm{P}_{\mathrm{MAX}}$ and $\mathrm{P}_{\mathrm{MIN}}$, respectively), whereas the remaining habitat types were little used $(0 \%-14 \%$ on average). During summer, there was an important decrease in the use of Mediterranean scrubland (29 and $57 \%$ on average during $\mathrm{P}_{\mathrm{MAX}}$ and $\mathrm{P}_{\mathrm{MIN}}$, respectively), and a considerable increase in the use of pastureland (23 and $26 \%$ on average during $\mathrm{P}_{\text {MAX }}$ and $\mathrm{P}_{\mathrm{MIN}}$, respectively). Badgers habitat use differed significantly between $\mathrm{P}_{\mathrm{MAX}}$ and $\mathrm{P}_{\mathrm{MIN}}(F=2.559, d f=6$, $P<0.048)$, though using the Bonferroni method we did not detect differences for any habitat type. Because of the overall differences, we assumed that badger habitat use differed between the two periods. During $\mathrm{P}_{\mathrm{MIN}}$, badgers used mainly the Mediterranean scrubland (71\% of locations annually on average, Table 4). Pastureland was used on average for $14 \%$ of the occasions. The remaining habitat types only averaged between $1 \%$ and $8 \%$. During $\mathrm{P}_{\mathrm{MAX}}$, there was an important decrease in the use of Mediterranean scrubland (on average $47 \%$ of locations), and a considerable increase in the use of marshes (on average $23 \%$ ). Within the study area, badger habitat use was not random (ten animals, $\chi^{2}=43.7, d f=5$, $P<0.001)$. They selected habitats in the following order: grassland $>$ Mediterranean scrubland $>$ marshes $>$ pastureland $>$ ash forest $>$ tree plantations. The three top-ranking habitat types were significantly preferred over tree plantations (all $t>3.1, d f=9$, all $P<0.02$ ). Within their individual home ranges, badger habitat use was not random during the $\mathrm{P}_{\mathrm{MIN}}$ (eight animals, $\left.\chi^{2}=16.3, d f=5, P<0.01\right)$. They selected the habitats in the following order: Mediterranean scrubland $>$ tree plantations $>$ ash forest $>$ marshes $>$ pastureland $>$ grassland. Mediterranean forest was preferred over the three bottom-ranking habitat types (all $t>2.4, d f=7$, all $P<0.05$ ). During $\mathrm{P}_{\mathrm{MAX}}$, badgers also selected the habitat within their individual home ranges (ten animals, $\left.\chi^{2}=19.8, d f=5, P<0.01\right)$. Mediterranean scrubland was significantly preferred over marshes, pastureland, and grassland (all $t>2.8, d f=9$, all $P<0.02$ )

There was a strong significant difference in the annual habitat use by the three species $(F=4.477, d f=12$, $P<0.0001)$. Differences found were significant for Mediterranean scrubland, pastureland, and ash forest (all $F>4.8, d f=2$, all $P<0.05$ ). Lynx used Mediterranean scrubland more often than did foxes, especially during $\mathrm{P}_{\text {MAX }}$ (Table 4). Foxes used pastureland much more frequently than did lynxes, mainly during $\mathrm{P}_{\mathrm{MAX}}$. In general, lynx and badgers showed rather similar habitat use (i.e., both used Mediterranean scrubland intensively). Badgers used Mediterranean scrubland more often than foxes during both $\mathrm{P}_{\mathrm{MAX}}$ and $\mathrm{P}_{\text {MIN }}$ (Table 4). Generally habitat use overlap was high, but not during $\mathrm{P}_{\text {MAX }}$ for fox-other carnivores (Fig. 2).

Rabbit abundance and relationship with carnivore habitat use

We did not detect differences in rabbit abundance between seasons $(P=0.339)$, even though the spring rabbit abundance index $(3.5 \pm 3.9)$ was 1.5 times higher than in other seasons $(2.2 \pm 2.1$ and $2.1 \pm 1.9$ in autumn/winter and summer, respectively). There were differences among habitats in rabbit abundance $(F=3.89, d f=4, P=0.037)$. Mediterranean scrubland and pastureland had the highest rabbit abundances whereas tree plantations and marshes had the lowest ones (Table 5). Percentages of area of each habitat types within individual home ranges correlated with rabbit abundance for badger $\left(r_{\mathrm{S}}=0.90, n=5, P=0.037\right)$, but not for foxes $(P=0.285)$, or lynx $(P=0.624)$. 
Table 5 Distance covered $(\mathrm{km})$ during rabbit surveys and annual mean rabbit abundance index for each habitat type. During rabbits surveys, small rabbits $(<200 \mathrm{~g})$ were not counted

\begin{tabular}{llll}
\hline Habitat & Distance $(\mathrm{km})$ & \multicolumn{2}{l}{ Rabbits $/ \mathrm{km}$} \\
\cline { 3 - 4 } & & Mean & $\mathrm{SD}$ \\
\hline Scrubland & 7.66 & 5.59 & 4.20 \\
Pastureland & 1.07 & 3.74 & 1.48 \\
Ash forest & 3.71 & 2.86 & 2.59 \\
Marshes & 1.76 & 0.68 & 0.74 \\
Tree plantations & 3.41 & 0.58 & 0.41 \\
\hline
\end{tabular}

These results suggest that badger home ranges were mainly composed of rabbit-rich habitat types, lynx home ranges were almost uniquely composed of the most rabbit-rich habitat type, and the fox home ranges composition included both rich and poor rabbit habitats (Tables 4,5 ). Number of radio-locations $/ \mathrm{km}^{2}$ of habitat did not correlate with rabbit abundance for any carnivore species, but badgers again had the highest correlation index $\left(r_{\mathrm{S}}\right.$ were $0.8,0.3$ and 0.0 for badger, fox, and lynx, respectively).

\section{Discussion}

\section{Interspecific patterns}

Our study confirms the trophic and habitat use specialization of lynx, as well as its crepuscular habits in Doñana (Delibes 1980; Palomares et al. 1991; Beltran and Delibes 1994). Though both fox and badger were omnivorous and used a variety of habitat types, they shared with lynx the same staple prey used intensively the Mediterranean scrubland, and were relatively crepuscular. All results confirmed our expectations based on previous knowledge of these two species in Doñana (Rau et al. 1985; Martin et al. 1995; Rodriguez et al. 1996) and elsewhere (Ginsberg and Macdonald 1991; Neal and Cheeseman 1996).

The high rabbit abundance in our study area and the nutritive value of this mammalian prey (which is known to affect predator preferences; Hespenheide 1975) may account for the high importance of rabbit in all carnivore diets. Interspecific differences in size of rabbit preyed on revealed contrasting foraging behaviors. In Doñana, badger behaves as a specialized predator of small rabbits which are dug out of their burrows (Martin et al. 1995). Foxes, typical of canids, chase their mobile prey (Kleiman and Eisenberg 1973; Murray et al. 1995) like medium-sized rabbits, though they also excavate some rabbit burrows (Rogers et al. 1994), and lynxes stalk their prey (Delibes 1980). On the other hand, crepuscular activity of all carnivore species is clearly related to the crepuscular habits of their main prey (rabbits; Villafuerte 1994). The more crepuscular a carnivore species was, the more medium and large rabbits in its diet. Thus, lynx which was the most crepuscular species, preyed most intensively on medium and large rabbits, and badger, which was the least crepuscular, preyed less intensively on those sizes of rabbits (Figs. 2, 4).

At the largest scale, all carnivores selected habitats suggesting they were sensitive to environmental factors such as vegetation cover and/or prey abundance. However, in general, carnivore habitat use did not correlate with rabbit abundance, although the larger amount of small rabbits in a carnivore species diet, the better the correlation between its habitat use and rabbit abundance (i.e., badgers consumed more small rabbits and showed the best correlation). Given that we did not count small rabbits during the surveys, this fact suggests that small and other-sized rabbit abundances correlated, and also suggests that carnivore foraging success on small rabbits was little affected by factors other than rabbit abundance (e.g., vegetation cover). For lynx, the lack of correlation is explained in terms of habitat specialization because lynx needs habitats both rich in rabbits and with high scrub cover (Delibes 1980; Palomares et al. 1991). For foxes, which behaved as a habitat generalist, a better correlation certainly would be expected. They used Mediterranean scrubland intensively during the resting period but not during the activity period, when they used pastureland more intensively. Explanations for this unexpected shift in fox habitat use are treated below.

\section{Niche relationships and carnivore coexistence}

Diet overlaps were higher during spring than in autumn/ winter in accordance with competition theory (e.g., Schoener 1982), which predicts a convergence of the diet of coexisting consumers when resources (rabbits) are abundant. However, diet overlaps remained high during summer even though rabbit abundance decreased 1.5fold. This unexpected result is likely related to a high incidence of rabbit diseases (e.g., myxomatosis) during summer in Doñana, and therefore foxes and badgers find a surplus of sick and thus easily captured rabbits (Rogers et al. 1994). Consequently, in our study, food competition was more likely during autumn/winter, since food overlaps were still high in this season. However, there are no adequate data or models on consumer requirements and prey availability necessary to establish whether competition occurred (Wiens 1993). On the other hand, in agreement with Greene and Jaksic (1983), we believe that differences in size classes on which the carnivores preyed did not reduce competition for food since different rabbit size classes are not self-renewable resources (e.g., Palomares et al. 1995). Nevertheless, differences in rabbit prey sizes for foxes and badgers implicate contrasting foraging modes that may play a decisive role regarding interference competition with lynx. Certainly, an individual fox chasing rabbits over long distances will probably be detected by a lynx more easily than an individual badger excavating a rabbit borrow. Similar effects of foraging modes on predation 
risk have been proposed for other terrestrial vertebrate predators (Huey and Bennett 1986).

High overlap values in activity might also be a result of the broad time intervals defined, and a finer delineation could reveal a higher segregation (Litvaitis and Harrison 1989). However, percent lynx activity remained consistently high throughout the circadian cycle (Fig. 4) making a neat temporal segregation difficult between lynx and the other two species. Therefore, it seems more likely that foxes reduced lynx predation by spatial behavior. Specifically, we propose that foxes reduced their use of Mediterranean scrubland (the richest rabbit habitat) during their activity period (when they are more detectable) to avoid encounters with lynxes which frequented this habitat. The lack of scrub cover in pastureland, which may increase the vulnerability of rabbits (Fedriani 1996) and thus optimize fox foraging effort in this habitat, might also explain the pattern of fox habitat use. Nevertheless, the high abundance of other kinds of shelters (burrows) in pastureland probably counteracts the effect of low scrub cover (Palomares and Delibes 1997). Furthermore, the generalist nature of fox makes it able to exploit efficiently very different habitats (Lucherini et al. 1995; Adkins and Stott 1998). Red foxes have been reported to avoid open and to select brushy habitats (despite the latter habitat being poorer in prey) to avoid hazardous encounters with coyotes (Canis latrans; Theberge and Wedells 1989).

Our approach did not take into account intraspecific variation, such as individual susceptibility to factors such as interspecific competition (Partridge and Green 1985). It is possible that spatial-temporal avoidance behaviors of some individuals (Major and Sherburne 1987) have facilitated the coexistence of these three carnivore species in our study area. In the same area, Palomares et al. (1996) observed that radio-tracked genets and mongooses avoided spatial overlap with lynxes because lynx kills them. This was not the case of radio-tracked foxes and badgers, whose home ranges largely overlapped with those of lynxes (Fedriani 1997). Further work is required to test for the presence of such avoidance behaviors between interspecific pairs of individuals with high overlap in habitat use during activity periods. For example, foxes and badgers apparently coexisted peacefully, even sharing some setts (Fedriani 1993), which might have been facilitated most of the year by using rather different habitats during activity. However, such spatial-temporal avoidance could play an important role in their coexistence during the summer when they overlapped highly in habitat use.

Our initial hypothesis is validated since the results strongly support the notion that foxes avoided lynx predation by habitat segregation during activity, whereas mechanisms other than niche segregation seem to allow badger and lynx coexistence. Since food overlaps among carnivores were always high, our conclusions challenge the view that food is the resource towards which spatial and behavioral means of distinguishing niches by pre- dators are ultimately directed (see Hespenheide 1975) but are consistent with MacArthur and Pianka (1966) and MacArthur and Wilson (1967), who predicted that for coexisting predators it is easier to adjust behavior (in this case, foraging habitat or method) to reduce competition, than to change food habits.

Acknowledgements We are grateful to Jose Ayala, Rafael Laffitte, Eloy Revilla, Javitxu Calzada, and Nuria Selva for field assistance. We thank Todd K. Fuller, John A. Litvaitis, and S.J. MacNaughton for critical review of our manuscript. Javier Bustamante assisted us with some statistical analyses. Hala Abdallah kindly reviewed our English. This study was supported by Direccion General de Investigacion Cientifica y Tecnica (projects PB-87/0405 and PB-94/0480), and with funding from a LIFE-project (DG XI) of the European Union. The senior author (J.M.F.) was supported by Ministerio de Educacion y Ciencia of Spain. We thank the Doñana Biological Station (CSIC, Spain) and the Department of Forestry and Wildlife Management (University of Massachusetts) for logistic support. The senior author particularly appreciates the support of Todd K. Fuller.

\section{References}

Adkins CA, Stott P (1998) Home ranges, movements and habitat associations of the red fox Vulpes vulpes in suburban Toronto, Ontario, Canada. J Zool 244:335-346

Aesbicher NJ, Robertson PA, Kenward RE (1993) Compositional analysis of habitat use from animal radio-tracking data. Ecology $74: 1313-1325$

Aldama JJ (1993) Ecología energética y reproductiva del lince ibérico (Lynx pardina, Temminck 1824) en Doñana. PhD thesis. Universidad Complutense de Madrid

Baker RJ (1987) GLIM 3.77 reference manual Numerical Algorithms Group, Oxford

Beltran JF (1991) Temporal abundance pattern of the wild rabbit in Doñana, SW Spain. Mammalia 55:591-599

Beltran JF, Delibes M (1994) Environmental determinants of circadian activity of free-ranging iberian lynxes. J Mammal 75:382-393

Crawley MJ (1993) GLIM for ecologists. Blackwell, Oxford

Delibes M (1980) Feeding ecology of the Spanish lynx in the Coto Doñana. Acta Theriol 25:309-324

Delibes M, Calderón J (1979) Datos sobre la reproducción del conejo, Oryctolagus cuniculus (L.), en Doñana, S.O. de España, durante un año seco. Doñana Acta Vert 6:91-99

Dixon KR, Chapman JA (1980) Harmonic mean measure of animal activity areas. Ecology 61:1040-1044

Fedriani JM (1993) Uso de tejoneras por zorros, Vulpes vulpes, y meloncillos, Herpestes ichneumon, en el Parque Nacional de Doñana. Bol. SECEM 3:9-10

Fedriani JM (1996) Dieta anual del zorro, Vulpes vulpes, en dos habitats del Parque Nacional de Doñana. Doñana Acta Vert 23:143-152

Fedriani JM (1997) Relaciones interespecíficas entre el lince ibérico, Lynx pardina, el zorro, Vulpes vulpes, y el tejón, Meles meles, en el Parque Nacional de Doñana. PhD thesis, University of Seville

Fedriani JM, Ferreras P, Delibes M (1998) Dietary response of the Eurasian badger, Meles meles, to a decline of its main prey in the Doñana National Park. J Zool 245:218-222

Ferreras P, Aldama JJ, Beltran JF, Delibes M (1994) Immobilization of the endangered Iberian lynx with xilazine and ketamine hydrocloride. J Wildl Dis 80:65-68

Ferreras P, Beltran JF, Aldama JJ, Delibes M (1997) Spatial organization and land tenure system of the endangered Iberian lynx (Lynx pardinus). J Zool 243:163-189

Ginsberg JR, Macdonald D (1991) Foxes, wolves, jackals and dogs. IUCN, Gland, Switzerland 
Greene HW, Jaksic FM (1983) Food niche relationships among sympatric predators: effects of the level of prey identification. Oikos 40:151-154

Hersteinsson P, Macdonald DW (1992) Interspecific competition and the geographical distribution of red and arctic foxes Vulpes vulpes and Alopex lagopus. Oikos 64:505-515

Hespenheide HA (1975) Prey characteristics and predator niche width. In: Cody ML, Diamond JM (eds) Ecology and evolution of communities. Harvard University Press, Cambridge, Mass, pp $158-180$

Huey RB, Bennett AF (1986) A comparative approach to field and laboratory studies in evolutionary biology. In: Feder ME, Lauder GV (eds) Predator-prey relationships: perspectives and approaches from the study of lower vertebrates. University of Chicago Press, Chicago, pp 82-98

Iriarte JA, Franklin WL, Johnson WE, Redford KH (1990) Biogeographic variation of food habits and body size of the American puma. Oecologia 85:185-190

Jaksic FM, Delibes M (1987) A comparative analysis of food-niche relationships and trophic guild structure in two assemblages of vertebrate predator differing in species richness: causes, correlations, and consequences. Oecologia 71:461-472

Kenward RN, Hodder KH (1996) RANGES V: an analysis system for biological location data. Institute of Terrestrial Ecology, Wareham, UK

Kleiman DG, Eisenberg JF (1973) Comparison of canid and felid social system from a evolutionary perspective. Anim Behav $21: 637-659$

Litvaitis JA, Harrison DJ (1989) Bobcat-coyote niche relationships during a period of coyote population increase. Can J Zool $67: 1180-1188$

Lockie JD (1959) The estimation of the food of foxes. J Wildl Manage 23:224-227

Lucherini M, Lovari S, Crema G (1995) Habitat use and ranging behavior of the red fox Vulpes vulpes in a Mediterranean rural area: is shelter availability a key factor? J Zool 237:577-591

MacArthur RH, Pianka ER (1966) On optimal use of a patchy environment. Am Nat 100:603-609

MacArthur RH, Wilson EO (1967) The theory of island biogegraphy. Princeton University Press, Princeton, NJ

Macdonald D (ed) (1984) The encyclopedia of mammals.George Allen and Unwin, London

Major JT, Sherburne JA (1987) Interspecific relationship of coyotes, bobcats and red foxes in western Maine. J Wildl Manage 51:606-616

Martín R, Rodríguez A, Delibes M (1995) Local feeding specialization by badgers (Meles meles) in a Mediterranean environment. Oecologia 101:45-50

Mills MGL, Biggs HC (1993) Prey apportionment and related ecological relationships between large carnivores in Kruger National Park. Symp Zool Soc Lond 65:253-268

Murray DL, Boutin S, O'Donoghue M (1994) Winter habitat selection by lynx and coyote in relation to snowshoe hare abundance. Can J Zool 72:1444-1451

Murray DL, Boutin S, O’Donoghue M, Nams VO (1995) Hunting behaviour of a sympatric felid and canid in relation to vegetation cover. Anim Behav 50:1203-1210

Neal E, Cheeseman C (1996) Badgers. Poyser, London

Palomares F, Delibes M (1991) Ecologia comparada de la gineta, Genetta genetta, y el meloncillo, Herpestes ichneumon, (L) (Mammalia, Viverridae) en Doñana. Bol R Soc Esp Hist Nat (Biol) 87:1-4

Palomares F, Delibes M (1992) Data analysis design and potential bias in radio-tracking studies of animal habitat use. Acta Oecol 13:752-758

Palomares F, Delibes M (1997) Predation upon European rabbits and their use of open and closed patches in Mediterranean habitats. Oikos 80:407-410
Palomares F, Rodriguez A, Laffitte R, Delibes M (1991) The status and distribution of the Iberian lynx Felis pardina in Coto Doñana area, SW Spain. Biol Conserv 57:159-169

Palomares F, Gaona P, Ferreras P, Delibes M (1995) Positive effects on game species of top predators by controlling smaller predator populations: an example with lynx, mongoose and rabbits. Conserv Biol 9:295-305

Palomares F, Ferreras P, Fedriani JM, Delibes M (1996) Spatial relationships between Iberian lynx and other carnivores in an area of south-western Spain. J Appl Ecol 33:5-13

Partridge L, Green P (1985) Intraspecific feeding specializations and population dynamics. In: Sibly RM, Smith RH (eds) Behavioural ecology: ecological consequences of adaptive behaviour. Blackwell, Oxford, pp 207-226

Pedlar JH, Fahrig L, Merriam HG (1997) Racoon habitat use at 2 spatial scales. J Wildl Manage 61:102-112

Pianka ER (1973) The structure of lizard communities. Annu Rev Ecol Syst 4:53-74

Pianka ER (1978) Evolutionary ecology. Harper \& Row, New York

Polis GA, Myers CA, Holt RD (1989) The ecology and evolution of intraguild predation: potential competitors that eat each other. Annu Rev Ecol Syst 20:297-230

Rau JR, Beltran JF, Delibes M (1985) Can the increase of fox density explain the decrease in lynx numbers at Doñana? Rev Ecol Terre Vie 40:145-150

Reynolds JC, Aebischer NJ (1991) Comparison and quantification of carnivore diet by faecal analysis: a critique, with recommendations, based on a study of the fox Vulpes vulpes. Mammal Rev 12:97-122

Rice WR (1989) Analyzing tables of statistical test. Evolution 43:223-225

Rodríguez A, Martín R, Delibes M (1996) Space use and activity in a Mediterranean population of badgers Meles meles. Acta Theriol 41:59-72

Rogers PM, Arthur CP, Soriguer RC (1994) The rabbit in continental Europe. In: Thompson HV, King CM (eds) The european rabbit: the history and biology of a successful colonizer. Oxford University Press, Oxford, pp 22-63

SAS (1990) SAS/STAT user's guide, version 6. SAS Institute, Cary, $\mathrm{NC}$

Schoener TW (1974) Resource partitioning in ecological communities. Science 185:27-39

Schoener TW (1982) The controversy over interspecific competition. Am Sci 70:586-595

Sih A, Crowley P, McPeek M, Petranka J, Strohmeier K (1985) Predation, competition, and prey communities: a review of field experiments. Annu Rev Ecol Syst 16:269-311

Theberge JB, Wedells CH (1989) Prey selection and habitat partitioning in sympatric coyote and red fox populations, southwest Yukon. Can J Zool 67:1285-1290

Travaini A, Ferreras P, Delibes M, Aldama JJ (1992) Xilazine hydrochloride-ketamine immobilization of free-living red foxes Vulpes vulpes in Spain. J Wildl Dis 28:507-509

Travaini A, Ferreras P, Aldama JJ, Fedriani JM, Delibes M (1994) Chemical immobilization of wild badgers Meles meles. Rev Med Vet 145:577-580

Valverde JA (1958) An ecological sketch of the Coto Doñana. Br Birds 51:1-23

Villafuerte R (1994) Riesgo de predación y estrategias defensivas del conejo, Orytolagus cuniculus, en el Parque Nacional de Doñana. PhD thesis, University of Cordoba

Wells H, King JL (1980) A general "exact test" for $\mathrm{N} \times \mathrm{M}$ contingency tables. Wildl Soc Bull 79:65-77

Wiens JA (1993) Fat times, lean times and competition among predators. Trends Ecol Evol 8:348-349

Zar JH (1984) Biostatistical analysis. Prentice-Hall, Englewood Cliffs, NJ 